\title{
State of the Art of Tunnel Fire Research
}

\author{
HAUKUR INGASON \\ Fire Technology \\ SP Technical Research Institute of Sweden \\ Box 857 \\ SE-50115 Borås, Sweden
}

\begin{abstract}
This paper gives an overview of the tunnel fire research, both experimental and theoretical work with the exception of computer modelling. The overview shows that the critical velocity for longitudinal flow in a tunnel is the single most well investigated fire phenomenon found in the tunnel fire research literature. This knowledge has reached a high level but there are still some areas that need to be investigated further. For example, very little work has been done on backlayering of smoke upstream a fire and cross-sectional effects on heat release rates, temperatures, flame lengths, fire spread and toxic conditions.

Extensive work using model scale tunnels has contributed with new information and clarified many phenomena but the lack of good large scale experimental data is and will be a key issue in near future. This concerns mainly the correlation between heat release rate and maximum ceiling temperatures, the influence of ventilation on maximum heat release rate and fire growth rate and fire spread in and between vehicles. The extensive theoretical work which has been conducted concerning the effects of ventilation on heat release rates needs to be further investigated in large scale tests.
\end{abstract}

KEYWORDS: tunnel fires, heat release rate, critical velocity, temperature, smoke, fire spread

\section{NOMENCLATURE}

\begin{tabular}{|c|c|c|c|}
\hline A & cross-sectional area $\left(\mathrm{m}^{2}\right)$ & $R$ & tunnel radius (m) \\
\hline$c_{p}$ & specific heat capacity of air ( $\mathrm{kJ} / \mathrm{kg} \mathrm{K})$ & $T$ & temperature $(\mathrm{K})$ \\
\hline $\mathrm{Fr}$ & Froude number & $u$ & air velocity $(\mathrm{m} / \mathrm{s})$ \\
\hline g & acceleration due to gravity $\left(\mathrm{m} / \mathrm{s}^{2}\right)$ & $v_{\text {crit }}$ & critical ventilation velocity $(\mathrm{m} / \mathrm{s})$ \\
\hline$H$ & tunnel height (m) & $v_{\text {crit }}^{*}$ & dimensionless critical velocity \\
\hline$k$ & constant equation (1) & $W$ & tunnel width (m) \\
\hline$K^{\prime}$ & constant equation (2) & Greek & \\
\hline$L_{b}$ & length of the backlayering distance (m) & $\varepsilon$ & constant equation (9) \\
\hline$L_{f}$ & flame length $(m)$ & $\rho$ & density $\left(\mathrm{kg} / \mathrm{m}^{3}\right)$ \\
\hline$\dot{Q}^{\prime}$ & $\begin{array}{l}\text { convective heat release rate per unit } \\
\text { width of the tunnel }(\mathrm{kW} / \mathrm{m})\end{array}$ & $\gamma$ & constant equation (9) \\
\hline Q & heat release rate (HRR) (kW) & Subscr & \\
\hline$\dot{Q}^{*}$ & dimensionless heat release rate & 0 & ambient conditions \\
\hline
\end{tabular}

\section{INTRODUCTION}

Tunnel fires are one of the most challenging research areas for a fire scientist. Tunnel constructions are complex in nature and the investment costs are sometimes astronomical. The fire load varies greatly at the same time as very few experiments with transport vehicles are available. The tunnel ventilation systems create complex and challenging atmospheres leading to numerous interesting physical phenomena. Such phenomena include, for example, three dimensional turbulent flow conditions around the fire or ventilation openings. In fact, tunnel research is comprised mostly of basic fire science phenomena, e.g., basic ignition phenomena, complex chemistry, fire and smoke spread, fuel and ventilation control, heat transfer, structural damage or human behaviour. Despite this fact, relatively small interest from the fire science community has been projected into the tunnel fire research field. The author has not been able to find any realistic explanation as to why this is the case. The interest ought to be higher simply because of the importance of the infrastructure transport systems for the society, the high investment costs and the challenging and interesting nature of this research area. One possible explanation is that the research needs has been 
initiated by engineers engaged in regulations, tunnel management and technical development of safety systems for tunnels, rather than universities, insurance companies or governmental owned research institutes.

In recent years the interest in fire safety science of tunnels has, however, increased mainly due to the increasing number of catastrophic tunnel fires and the increasing number of tunnels built. Numerous universities, research institutes and large engineering companies have become involved in large national infrastructure projects, e.g., the Channel Tunnel project connecting UK and France. This project was a real engineering challenge where the fire safety aspects played an important role. The Channel Tunnel project enhanced and created new fundamental knowledge, especially in the UK. This new knowledge, together with better educated fire protection engineers and scientists, increased our ability to conduct performance based design of these new large tunnels. This, in turn, has required better engineering methods and technology such as CFD (Computational Fluid Dynamics). A good sign of the increasing interest from the fire safety community is the Handbook of Fire Safety in Tunnels edited by Beard and Carvel [1]. Amongst other things, this book contains the first published full treatment of Fire Dynamics in Tunnels [2]. This book will definitely enhance our knowledge and understanding of basic tunnel fire phenomena mainly because the tunnel industry is still lacking good fire safety expertise.

The educational part of the tunnel fire safety science is still in its start up phase. Graduate courses in fire safety engineering worldwide do not generally include courses in fire dynamics or safety in tunnels. The author has given PhD courses in fire dynamics in tunnels at the Mälardalen University in Sweden. Such courses are unique but there is no doubt that tunnel research will be an important research and education area in the future and that fundamental courses will be integrated into the education internationally in due time.

The overview presented here shows that the efforts of different countries in the field of tunnel fire research vary. Fire scientists in the UK have traditionally been very active in this field. The Fire Research Station (FRS) in Boreham Wood had numerous fire researchers that contributed in the early stages. As mentioned previously, large infrastructure projects on tunnels may have an effect on the national research efforts on tunnel fires. The best example of this is when the Channel Tunnel project was established in the beginning of the 90's. This resulted in many research projects in the UK, engaging numerous fire researchers. The researchers at the Health and Safety Executive (HSE) in Buxton contributed with new experimental and theoretical knowledge on ventilation and heat release rates in tunnel fires [3-5]. Their work focused on critical velocity, modelling techniques, smoke spread and CFD validation. In the late 90's, a group of fire scientists at the Herriot-Watt University in Edinburgh and from Edinburg University started to do research on fire spread in tunnels and the influence of ventilation on heat release rates [6-9]. There are of course other national fire research groups that have worked with tunnel research but they have usually been smaller. Fire scientist from Sweden, Norway, Finland, Netherland, French, Germany, Australia, USA, Japan, Korea and China have all been involved in national projects on tunnel related fire research.

Important new knowledge has been generated as part of European research projects within the $5^{\text {th }}$ and the $6^{\text {th }}$ Framework programme sponsored by the European Commission. These projects are not presented here but examples of such projects include Upgrading Methods for Fire Safety in Existing Tunnels (UPTUN), Durable and Reliable Tunnel Structures (DART), Thematic Network on Fire in Tunnels (FIT), Large Scale Underground Research Facility (LSURF) etc.

Other important research works that were not originally carried out for tunnels, but for mines and ducts, constitute a very good basic knowledge for fires in tunnels [10-12].

In order to give an overview of the state of the art of tunnel fire research, some of the major research efforts to date are summarised here. This includes both theoretical and experimental work carried out world wide with the exception of computer modelling work.

\section{OVERVIEW OF THEORETICAL WORK}

\section{Critical velocity}

The first theoretical work related to tunnel fire science is found in 1958 by Thomas [13], on the movement of buoyant fluid against a stream and the venting of underground fires. In this article the main focus was on 
backlayering of hot smoke (see Figure 1) but in 1968 Thomas [14] presented the concept of critical velocity in duct flow. The critical velocity is defined as the longitudinal velocity needed to prevent any type of backlayering of hot gases. Based on the Froude number (Froude $=1$ when the buoyancy and inertial force are equal), Thomas derived the following semi-empirical equation for the critical velocity:

$$
v_{c r i t}=k\left(\frac{g \dot{Q}^{\prime}}{\rho_{0} c_{p} T}\right)^{1 / 3}
$$

where $v_{\text {crit }}$ is the critical ventilation velocity, g is the acceleration due to gravity, $Q^{\prime}$ is the convective heat release rate per unit width of the tunnel, $\rho_{0}$ is the ambient density, $c_{p}$ is the specific heat capacity of air, $\mathrm{k}$ is constant (Thomas found that $\mathrm{k}=1$ gave a fair agreement with test data) and $T$ is smoke temperature.

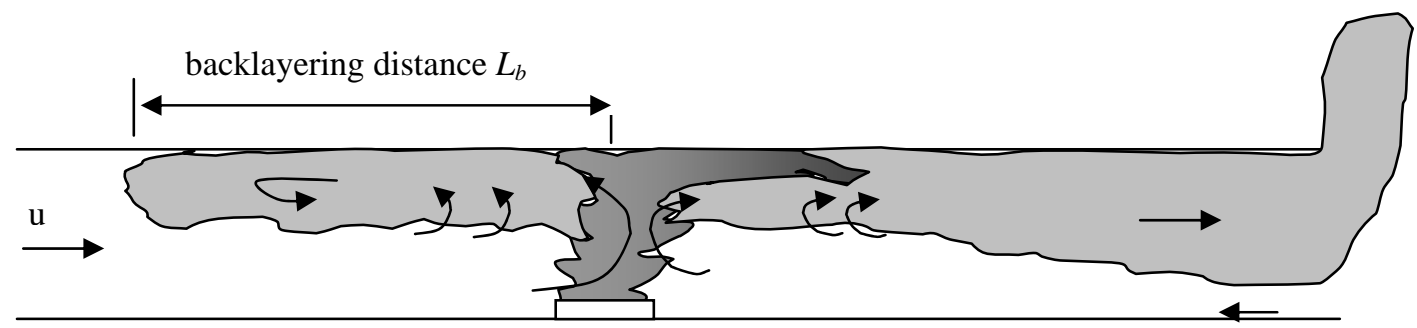

Figure 1 A schematic sketch showing the backlayering distance of smoke in a longitudinal tunnel flow.

Hinkley [15] also worked on the subject of critical velocity, but in a different application (one end closed corridor in a shopping mall), and came up with a similar cube-root relationship to that of Thomas [14]:

$$
v_{\text {crit }}=K^{\prime}\left(\frac{g \dot{Q} T}{\rho_{0} c_{p} T_{0}^{2} W}\right)^{1 / 3}
$$

where $\mathrm{W}$ is the width, $T_{0}$ is ambient temperature and $K^{\prime}$ was found to be 0.8 , determined from experiments on the movement of the hot gas layers in relatively short corridors without forced ventilation. Hinkley assumed that the magnitude of ventilation velocity was equal to that of the hot gas velocity. Heselden [16] continued with Hinkleys approach by including constants extracted from a limited set of data from large scale tests in Glasgow. Heseldens work was widely used as the basis for specifying recommendations on critical velocities in road tunnels [17]. Thomas, Hinkley and Heselden, have all made a considerable contribution to the fire safety community in general but their efforts have also had a significant impact on improving our basic knowledge in tunnel fire engineering. In particular the work by Heselden $[16,18]$ had a great impact on the way engineers treated design fires and ventilation. His initial estimates on the type and characteristics of fires and the levels of heat release rates for cars (5 MW) and Heavy Goods Vehicles (20 MW) still constitute the basis for many design guidelines. His clear description of the characteristics of tunnel fires is admirable and still holds for the most part. His discussion of design fires for Heavy Goods Vehicles fires, however, has been renewed due to new experimental data [19, 20].

The pioneering work on critical velocity by Thomas has been analysed further by many researchers. The common factor with these studies is the focus on different parameters that can affect the critical velocity, including: the tunnel geometry, tunnel slope or plume flow. For example in 1982, Danziger and Kennedy [21] presented a set of semi-empirical equations based on Froude number modelling, similar to Thomas work, which included a grade correction factor to calculate the critical velocity for sloping tunnels. This model was included in a computer model called SES (Subway Environmental Simulation).

The main problem with the Thomas critical velocity correlation (equation (1)), which has a 1/3 exponent, is that it is only valid for flame heights lower than the ceiling height [22]. In order to solve this problem, Ota and Atkinson [22] conducted important work using dimensional analysis. They found that for low heat release rates the test data followed Thomas cube root relation but then flattened out. They sought a simple explanation of the variation of critical velocity with heat release rate by examining the buoyancy head 
produced by fire plumes with flames falling well short of, or extending along, the ceiling [17]. They suggested Froude scaling and presented the following correlations for critical conditions:

$$
v_{c r i t}^{*}=\frac{v_{c r i t}}{\sqrt{g H}}
$$

and

$$
\dot{Q}^{*}=\frac{\dot{Q}}{\rho_{0} c_{p} T_{0} \sqrt{g H^{5}}}
$$

where $v_{\text {crit }}^{*}$ is the dimensionless critical velocity, $v_{\text {crit }}$ is the critical velocity, $H$ is the height of the tunnel, $\dot{Q}$ is the heat release rate and $\dot{Q}^{*}$ is the dimensionless heat release rate. Equation (3) and (4) are governed by the following constraints:

$$
\begin{array}{ll}
v_{c r i t}^{*}=v_{\max }^{*}\left(\frac{\dot{Q}^{*}}{0.12}\right)^{1 / 3} & \text { for } \dot{Q}^{*}<0.12 \\
v_{\text {crit }}^{*}=v_{\max }^{*} & \text { for } \dot{Q}^{*}>0.12
\end{array}
$$

The value of $v_{\max }^{*}$ varies between 0.22 and 0.38 depending upon which burner was used during the various experiments [22]. By calculating $\dot{Q}^{*}$ and then $v^{*}$, the critical velocity is given by equation (3). For low values of $Q^{*}, v_{\text {crit }}^{*}$ increases with $Q^{* 1 / 3}$. But for higher values of $Q^{*}, v_{\text {crit }}^{*}$ is more or less constant. Atkinson and $\mathrm{Wu}$ [23] extended this work using the same dimensional analysis for large fires but derived corrections for sloped tunnels varying between 0 to 10 degrees. Wu and Bakar [24] as well as Lee and Ryou [25] continued in similar manner, but used hydraulic diameter instead of tunnel height in their dimensional analysis of the experimental test results. This was done in order to better correlate the effects of the aspect ratio of the tunnel to the test data. The work by Hwang and Edwards [26] summarises well the period of dimensional analysis of the critical velocity. They used CFD analysis in their work together with work originating from a different research area; namely mining.

A new type of theoretical approach for critical velocity was adopted by Kunsch [27], who developed a simple analytical model to account for the physical models for a rising plume deflected at the ceiling and the integration of relevant equations for backlayering flow. His work provides a sound basis for further development of these models. Kunch model precdicts the existence of a limit value of the dimensionless critical velocity. For large values of heat release rate, the dimensionless critical velocity becomes independent of the heat release rate and approaches a value of 0.42 [28]. Vauquelin et al. [28-30] has presented interesting papers on critical velocity using test data from model scale tests with buoyant fluid. In the paper on "confinement velocity", Vauquelin and Telle [29] apply the concept of critical velocity for longitudinal flow in order to control the smoke gases from two different directions using extraction ventilation. This type of thinking is new and innovative and ought to be investigated further.

It is clear that the critical velocity (no backlayering) is the single most well investigated fire phenomena found in the literature of tunnel fire research. The level of knowledge is high but there are still some areas that need to be investigated further. The majority of the theoretical models that describe the concept of critical velocity are based on a semi-empirical approach. The semi-empirical models consider slope, aspect ratios, objects in the flow and hydraulic diameters but all the test data presented is based on steady state conditions. No effects of the dynamic fire development nor heat losses to surrounding walls on the critical velocity have been investigated. Some of the work is based on analytical methods but these methods are more complicated by nature. They may, however, exhibit a greater potential in terms of improvements to these models, especially the effects of dynamic fire development and heat losses. 


\section{Backlayering of smoke}

Thomas [13] has established theoretical correlations between the hot plume flow above the fire and the backflow of hot gases upstream the fire in a longitudinal flow (see Figure 1). The equation Thomas established was as follows:

$$
\frac{L_{b}}{H}=0.6\left(\frac{2 g H \dot{Q}}{T \rho_{0} c_{p} u^{3} A}-5\right)
$$

where $\frac{2 g H Q}{T \rho_{0} c_{p} u^{3} A}>5, \quad L_{b}$ is the length of the backlayering distance (m) and $T$ is the average fire temperature (K). This correlation has not been validated by experimental data and it is seldom referenced or investigated by researchers. This equation could be used to estimate the critical velocity, i.e when $L_{b} / H=0$. A more well known relationship is that developed by Vantelon et al. [31] who presented a simple model for predicting the length of a backed-up smoke layer, $L_{b}$ :

$$
\frac{L_{b}}{R} \propto\left(\frac{g \dot{Q}}{c_{p} \rho_{0} T_{0} u^{3} R}\right)^{0.3}
$$

where R is the tunnel radius. The proportionality constant for equation (6) has not been determined experimentally. Ingason [2] discusses this constant (assuming the exponent as $1 / 3$ instead of 0.3 ) and found based on data from numerous model scale tests, that this constant varied between 0.6 to 2.2. There is a need to compare these correlations with large scale experimental data. Ingason [32] used equations (5) and (6) to correlate model scale data on backlayering and found that equation (5) gave a better correlation. He was also able to show that equation (5) yielded a critical velocity of about to $3.4 \mathrm{~m} / \mathrm{s}$ and $4.17 \mathrm{~m} / \mathrm{s}$ depending on the tunnel height. It is encouraging to see that the original work by Thomas [13] gives such good results.

\section{Influence of ventilation on fire spread}

In the late 90's a group of fire scientists at the Herriot-Watt University in Edinburgh and from Edinburg University started research on fire spread modelling which is still today the only comprehensive treatment of fire spread in a tunnel. Beard et al. [6,33] examined the ignition of objects downstream of an existing fire in a tunnel. Beard et al. derived series of models under the generic title FIRE-SPRINT (Fire Spread in Tunnels). This is based on a non-linear model, the first version of which was FIRE-SPRINT A1 (Fire Spread in Tunnels, Model A, Version 1), which predicts the conditions for fire spread from one object to another within a tunnel with longitudinal ventilation. However, the flames do not extend downstream of the initial fire. The model identifies unstable states within the system and associated instability with the onset of fire spread. The model is based on average temperatures within a control volume where radiant feedback from the hot gases in the control volume is essential to the development of the thermal instability. The instability is correlated with a jump in the temperature of the gases in the control volume. This jump is associated with the point at which spread from an initial fire to a target object would be expected. Beard et al. explain that it should not be assumed that this is necessarily the only possible mechanism for the fire spread from one object to another in a tunnel (see definition of fire spread mechanism below). It is, however, assumed that this thermal instability corresponds to one mechanism of fire spread. The tunnel model has been developed further since this groundbreaking work (FIRE-SPRINT A2 [7, 34]), where the flames extend downstream from the initial fire and over the entire length of the target object without impinging on it. There is also a third version, FIRE-SPRINT A3 [35], available which makes the same assumptions as A2 but includes a thicker flame section between the initial fire and target fire. The flame impingement has also been considered and has led to the development of the model FIRE-SPRINT B1 [36]. The main problem for the developers has been the lack of experimental data to validate the program. 
Rew and Deaves [37] postulated various mechanisms for fire spread based on work concerning the Channel Tunnel Fire in 1996 [38]. The first mechanism is flame impingement. Due to low the ventilation rate, the flames are deflected by the presence of the ceiling, mainly in the direction of the ventilation flow. The flames visually 'crawl' along the ceiling above the vehicles. The second one is surface spread, which implies flame spread across the surface of the fire load. The third is remote ignition, i.e, the conditions at vehicles which are not very close to the initial fire are raised to the point of spontaneous ignition due to the high temperatures produced by the fire. The fourth is fuel transfer, which entails spread of the fire through liquid spread from leaking fuel tanks or debris downwind of the fire. The last one is explosion, i.e., explosion of fuel tanks may spread burning fuel to adjacent vehicles.

Rew and Deaves concluded that although all the above mechanisms may have contributed to fire spread in the Channel Tunnel incident, the primary mode of fire spread between wagons was due to flame impingement. They estimated the flame lengths as a function of the heat release rate and the ventilation flow rate. They assumed that the gas temperature at the flame tip was $600{ }^{\circ} \mathrm{C}$ and compared that to the criterion given by Heselden [16] for ignition of vehicles in tunnels $\left(580^{\circ} \mathrm{C}\right)$. This value appears to be very close to the values cited previously for the spontaneous ignition of materials. If the vehicles are exposed to temperatures in this range for some time they will ignite, without the need for piloted ignition (i.e. by spontaneous ignition). If the flames are in the vicinity of the pyrolysing material, the material will probably ignite at lower temperatures (through piloted ignition).

Lönnermark and Ingason [39] carried out an analysis of fire spread during four large-scale fire tests that were performed in the Runehamar tunnel in 2003 [19, 40]. The fire loads consisted of mock-ups simulating a Heavy Goods Vehicle (HGV) trailer. The fire spread downstream of the HGV trailer mock-ups was studied, both to large targets with the same type of commodities as used in the trailer mock-up for each tests, and to small pieces of wood and plastic, placed at different distances from the fire. The purpose was to determine a critical distance for fire spread between HGV trailers for different heat release rate histories. The time to ignition of a second object and fire spreading distances were estimated from post-visual observations and temperature measurements.

\section{Influence of ventilation on maximum heat release and fire growth rate}

The effect of longitudinal ventilation on the fire development in HGV fires is an important issue for tunnel designers. The interaction between the ventilation flow and the heat release rate has been investigated extensively by the research group from Heriot-Watt University [8, 9, 41]. They recognized that data was available from a number of different fire tests in various tunnels and with different boundary conditions, but that no consistent data was available. Therefore, it was not possible to use traditional statistical methods to analyse the data. Their method to solve this was by using a probabilistic approach; i.e., for example, the Heat Release Rate (HRR) of a HGV could increase by much more than a factor of four for a longitudinal flow rate of $3 \mathrm{~m} / \mathrm{s}$, but that the most likely HRR enhancement is approximately a factor of four at $3 \mathrm{~m} / \mathrm{s}$ and a factor of ten at $10 \mathrm{~m} / \mathrm{s}$. They also found that the fire growth rate could increase by a factor of five for 3 $\mathrm{m} / \mathrm{s}$ and by factor of ten for $10 \mathrm{~m} / \mathrm{s}$. It was also seen that the enhancing effects of ventilation for small pool fires is much less significant than that for HGV's (it may be reduced by $40 \%$ ), while that for large pool fires tended to increase by $50 \%$. For car fires, the enhancement of the ventilation rate on the heat release would not be significantly different relative to a car in a naturally ventilated tunnel. The fire growth rate for car fires would not be significantly influenced by forced ventilation rates of $1.5 \mathrm{~m} / \mathrm{s}$. A Bayesian probabilistic approach was used to refine estimates, made by a panel of experts, with data from experimental fire tests in tunnels. Due to the lack of systematic experimental data, the authors declared early that when new data becomes available the results will be refined. This has also been done in publications such as references [42, 43].

Researchers at the SP Technical Research Institute of Sweden have performed numerous experimental investigations, both large scale and model scale, that partly fill the gap in experimental data concerning the influence of ventilation on fire spread and heat release rates [19, 32, 39, 40, 44-46]. The PhD Thesis by Lönnermark in 2005 [40], summaries well the work carried out at SP and gives a broad description of the new knowledge introduced into tunnel fire research. Lönnermark's thesis [40] constitutes a milestone in tunnel fire research, with the work at the Runehamar tests [19, 40, 47, 48] as a major contribution. 
Apart from the Runehamar tests, several model and intermediate scale fire tests have been carried out by SP. The aim of the model study by Ingason [32] was to show the importance of the ventilation rate on the maximum heat release rate and the fire growth rate for solid fuels (wood cribs in this case), that are comparable from a porosity point of view. Comparing the effects of ventilation on fuels with significantly different porosity and ventilation conditions is not advisable as it may give an unfair comparison of the effects. The effects may be overestimated if one compares a burning wood crib with low porosity at quiescent conditions to a burning wood crib with a high porosity and high wind conditions. In order to investigate the effects of ventilation on the burning characteristic of the wood cribs, a plot was made of the data. The comparison may give slight erroneous results since the influence of the surrounding walls (reradiation etc.) with no ventilation on the mass burning rate is not included. The model scale tests [32] show that that the maximum heat release rate per unit fuel area increases with increasing longitudinal ventilation rate for a well ventilated wood crib. The increase here is not more than a factor of 1.55 , as can be observed in the left figure of Figure 2. For a wood crib with lower porosity this value was not higher than a factor of 2 [46]. The aim was also to investigate the effects of longitudinal ventilation on fire growth rates. The linear fire growth rate, $\Delta Q / \Delta t$, was taken from the time the heat release rate was $20 \mathrm{~kW}$ up to the time when it reached $100 \mathrm{~kW}$.
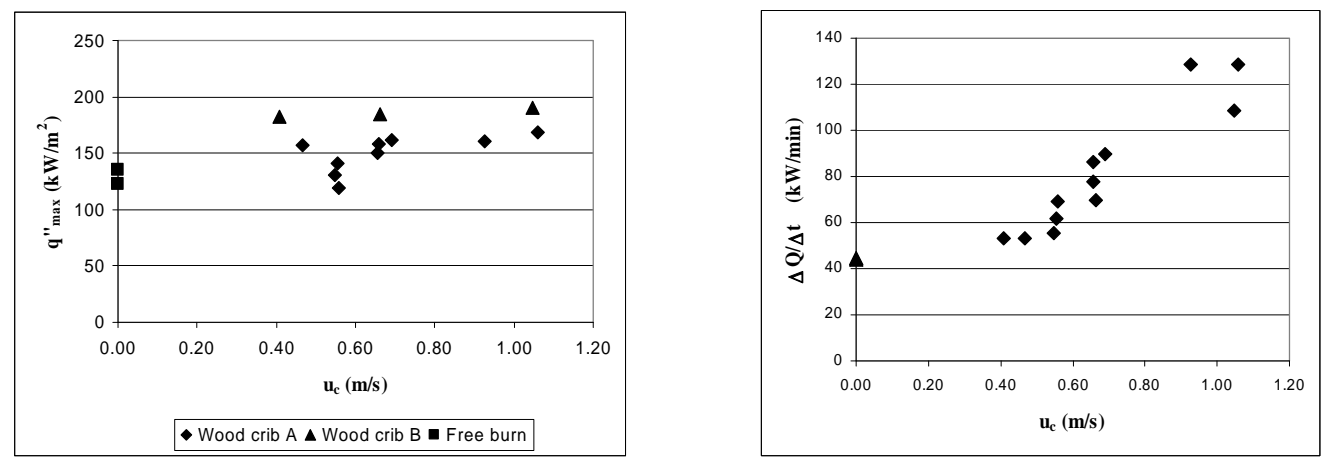

Figure 2 To the left, the maximum heat release rate per unit area fuel surface as a function of the longitudinal ventilation rate, $u_{c}$, for two different types of well ventilated wood cribs. To the right the fire growth rate for the wood cribs tested as a function of the longitudinal ventilation rate [32].

The data on fire growth rates given in reference [32] is also plotted in Figure 2 (right) as a function of the longitudinal ventilation rate, $u_{c}$. The results show that the influence of the longitudinal ventilation rate on the fire growth rate is much higher than on the maximum heat release rate. This has to do with the way the fire spreads along the crib. The increase is related to a more effective heat transfer from the flames to the fuel surface (e.g. tilted flames enhance the flame spread) and more effective transport of oxygen into the fuel bed. It also affects the glowing pyrolysis (oxidation of the char) of the wood cribs. The fire may be locally under-ventilated under normal conditions (e.g densely packed wood cribs or goods) but in a forced ventilation flow the transport of oxygen to the under-ventilated regions enhances the combustion rate. Beyond a certain air velocity, however, convective cooling can compete with the heat transfer from the flames and the burning rate and thereby the heat release rate may be reduced. The fire growth rate increase at a velocity $0.62 \mathrm{~m} / \mathrm{s}$ (corresponding to $3 \mathrm{~m} / \mathrm{s}$ in large scale) is in the order of 2 times the fire growth rate at ambient conditions and for $1.04 \mathrm{~m} / \mathrm{s}$ ( $5 \mathrm{~m} / \mathrm{s}$ in the large scale) it is in the order of three. It should be emphasised that any type of blockage of the fuel against the wind flow can totally change the fire growth rate [46]. As the fire growth rate is one of the most important design parameters for tunnel safety these results are considered as important.

An interesting observation concerning the work on influence of forced ventilation flow on heat release rates comes from an early study by Harmathy [49]. He concluded that the heat released by the oxidation of the char plays an important role in the process of pyrolysis and thereby the heat release rate. Non-charring fuels do not exhibit this influence on the heat release rate. This explains why the increase is not higher than is obtained in the model scale tests by SP for fuel that is not under-ventilated under normal conditions. This is crucial for our understanding of the effects of ventilation rate on heat release rates in tunnel fires. A possible explanation for why Carvel et al. determine such a high increase in the maximum heat release rate 
for HGV is therefore the way the fuel was compared. Fuel that is under-ventilated during ambient (quiescent) or natural ventilated conditions exhibits much higher increase than fuel that is not underventilated under ambient or natural ventilated conditions.

\section{Influence of tunnel size on heat release rate}

The effect of the tunnel geometry on heat release rate is an interesting research field. Carvel et al. [50] compared the increase of heat release rate due to the tunnel geometry to a similar situation under ambient outdoor conditions. A number of different experimental test series published in the literature were studied. The work included experiments involving liquid pools, wood cribs, and cars. The authors came to the conclusion that the width of the tunnel has a significant influence on the heat release rate from a fire in a tunnel. The results were explained by the surrounding wall and hot gas radiation to the pool surface, the temperature inside the tunnel, and the flow pattern near the fire. The analysis indicated that the height of the tunnel did not significantly effect the heat release rate enhancement. Lönnermark and Ingason [46, 51] investigated the effect of geometry on the heat release rate using model scale tests, and found that the dependency of the mass loss rate and the heat release rate on the tunnel dimensions differ, especially for pool fires. The effect of the height and the width on the mass loss rate and heat release rate depends on the starting conditions. For a pool fire in a tunnel with relatively small height or width, an increase in tunnel dimensions leads to an increase in fire size while for larger heights and widths, an increase in tunnel dimensions leads to a decrease in fire size.

\section{Flame length}

Very little effort has been put into analysing flame lengths in tunnels. This is an important area, especially due to the fire spread risk. Rew and Deaves [37] presented a flame length model for tunnels, which included heat release rate and longitudinal velocity but not the tunnel width or height. Much of their work is based on the investigation of the Channel Tunnel Fire in 1996 [38], test data from the HGV-EUREKA 499 fire test [52] and the Memorial Tests [53]. They defined the horizontal flame length, $L_{f}$, as the distance of the $600{ }^{\circ} \mathrm{C}$ contour from the centre of the HGV or the pool, or from the rear of the HGV. The flame length from the rear of the HGV was represented by the following equation:

$$
L_{f}=20\left(\frac{\dot{Q}}{120}\right)\left(\frac{u}{10}\right)^{-0.4}
$$

here $Q$ is given in MW and $u$ in $\mathrm{m} / \mathrm{s}$. This equation is a conservative fit to a limited set of data obtained from the HGV-EUREKA 499 test. Equation (7) tells us that the longitudinal ventilation shortens the flame length as the velocity increase. Oka et al. [54] and Kuwana et al. [55] have examined the variation of flame length and tilt for flames which did not reach to the ceiling. They obtained a similar dependence on ventilation rate although the dependence on heat release rate was somewhat weaker[56]. Lönnermark and Ingason [39] developed a flame length correlation based on a combination of a plume flow correlation and equation (7):

$$
L_{f}=\frac{1370 \cdot \dot{Q}^{0.8} u^{-0.4}}{\left(T_{f t}-T_{0}\right)^{3 / 2} H^{3 / 2}}
$$

This correlation worked very well for the Runehamar data. Further work on flame lengths in tunnels is definitely needed, especially in the case of natural and transverse ventilation.

\section{Maximum gas temperature}

There are number of temperature-time curves available for design of load bearing structures in tunnels. The most common is the standard curve used in laboratory testing, e.g. ISO 834. This curve represents material found in buildings and is not really relevant for tunnels, mainly because of the fact that it shows a slower temperature rise than has been found from tunnel experiments. ISO 834 has been used in many countries for tunnels, but it rapidly became clear that it does not represent all material, e.g. petrol, chemicals etc. and 
therefore a special curve, the hydrocarbon curve (the HC-curve), was developed in the 1970's. The HCcurve has mainly been used in the petrochemical and off-shore industries but it has also gained some acceptance for tunnel applications. Special temperature curves have been developed in some countries to specifically simulate hydrocarbon fires in tunnels. Examples of such curves are the RABT/ZTV Tunnel Curve in Germany, modified $\mathrm{HC}_{\mathrm{inc}}$ in France, and the Rijkswaterstaat Tunnel Curve (the RWS Curve) in the Netherlands. There are a number of large-scale tests available with gas temperatures in the vicinity of the fire source which can be compared to the temperature development in these standard curves.

The highest gas temperatures for tunnel fires available in the literature are from the Runehamar test series [47] and from petrol liquid fire tests in tunnels [57] with small-cross sections. These fires resulted in gas temperatures in the range of $1200-1365{ }^{\circ} \mathrm{C}$. These high temperatures are in agreement with the highest temperatures in the RWS and HC curves for tunnel fires. There is a correspondence between high heat release rate and high temperatures but high temperatures also appear to be related to the type of fuel, fuel geometry, and size and cross-section of the tunnel. For high heat release rates ( $\geq 35 \mathrm{MW})$ the gas temperatures become high $\left(\geq 900{ }^{\circ} \mathrm{C}\right)$, with the exception of the tests in the Memorial tunnel test series with high ceiling height and $100 \mathrm{MW}$. This observation is applicable even when the ventilation rate is high $(\geq 3 \mathrm{~m} / \mathrm{s}$ ). This can be explained by the fact that for high heat release rates the flames impinge on the ceiling and the combustion zone, where the highest temperatures are usually obtained, is situated close to the ceiling, even when the longitudinal ventilation deflects the flames. All together these results indicate that the type of fuel, its geometrical shape and size, the tunnel cross-section, and the combustion efficiency are important parameters for the temperature level. In conclusion we can say that, when the combustion zone (usually up to about two-fifths parts of the free flame height) extends up to the tunnel ceiling and we reach optimal ventilation in the combustion area, the highest ceiling temperatures will be obtained. When the longitudinal ventilation is increased the cooling effects dominate and the temperature drops again.

There is a need to develop correlations between the heat release rate, ventilation rate, tunnel geometry and fuel type and shape. This may already be in place as a group of Japanese scientists have recently conducted some very important work in the field of heat release rate and ceiling temperatures [55, 58]. Based on own model scale and large scale tests, Kurioka et al. [58] have derived correlations for the maximum ceiling temperature, through dimensional analysis:

$$
\frac{\Delta T_{\max }}{T_{0}}=\gamma\left(\frac{Q^{* 2 / 3}}{F r^{1 / 3}}\right)^{\varepsilon}
$$

under the constrain that:

$$
\begin{array}{lll}
Q^{* 2 / 3} / \mathrm{Fr}^{1 / 3}<1.35 & \gamma=1.77 & \varepsilon=6 / 5 \\
1.35 \leq Q^{* 2 / 3} / \mathrm{Fr}^{1 / 3} & \gamma=2.54 & \varepsilon=0
\end{array}
$$

where $Q^{*}=\frac{Q}{\rho_{0} c_{p} T_{0} \sqrt{g H_{d}{ }^{5}}}$ and $\mathrm{H}_{\mathrm{d}}$ is the height from fuel surface to ceiling. This correlation can be used to calculate the gas temperature in the ceiling of a tunnel with a longitudinal ventilation flow and different tunnel heights. The approach given by these Japanese researchers is very promising. Their work needs to be analysed further by comparing these results with large scale tests carried out worldwide.

Lönnermark and Ingason [46] carried out model scale tests using two different types of fuels, wood cribs and heptane pool fire, and investigated the correlation between the maximum gas temperature, ventilation rate and the size of the cross-section of a tunnel. They found that the maximum gas temperature is affected by the dimension of the tunnel. In general there was a decrease in the temperature with increasing dimension, but not near the fire where an increase in gas temperature could be seen. For the tunnels with a small cross-section, the temperature is relatively uniform, while an increased stratification and difference between average temperature and ceiling temperature can be observed when the width or height of the tunnel is increased. 


\section{OVERVIEW OF EXPERIMENTAL LARGE SCALE WORK}

Numerous large scale fire tests in tunnels have been carried out. Experience shows that the mass loss rate, heat release rate, smoke spread and the ceiling gas temperature are the parameters mostly documented. A dozen scientifically founded large-scale fire test programs have been carried out to date as can be seen in the summary given by Ingason [59].

The focus has mainly been on the heat and smoke spread and how different ventilation systems influence these parameters. The quality of large-scale tests carried out in the 60's to 80's varies considerably and in all these tests there is a lack of the key fire hazard parameter: the heat release rate. Further, the boundary conditions (wind at portals, air temperatures, lining surface etc) were usually not the most favorable for validation of advanced computer models. These tests were performed to fill a gaping lack of knowledge concerning the influence of the ventilation systems on tunnel fires rather than to fulfill the need for academic studies and validation of CFD-fire models.

The first series of large-scale tunnel fire test series were performed in the 60's and the 70's in Europe [60] [61] [61-63]. Many of these tests were reported with admirable detail concerning the test data and the test set-up. They were mainly directed towards solving fire problems of road tunnels in Europe and they had a major influence on the technical standards of that time, an influence which continues today. Grant et al. [17] considered these tests as 'tantalizing snapshots' primarily due to the inadequate heat release data. A less known large-scale test series was carried out in Japan in the late 70' and beginning of the 80's [64]. The tests were carried out in a full-scale test tunnel and in a full-size road tunnel. This was the first time full size vehicles (cars, buses) were used in a large-scale test series in a tunnel but unfortunately no heat release rate measurements were carried out. Some weight loss estimations were, however, carried out. In general we can say that the tests carried out in the 60's and the 70's had, and still have, a major influence on the standards and guidelines used for fire safety in tunnels.

A new era was started in tunnel fire testing with the use of the oxygen consumption calorimetry. In the early 80 's, oxygen consumption calorimetry became a standard tool in fire laboratory worldwide. When the EUREKA tests were performed in the beginning of 90's, these tests denoted a milestone concerning new and valuable information for tunnel engineers. In particular in terms of the great variety in the heat release rate data for vehicle types such as cars, train coaches, subway coaches and an articulated lorry loaded with furniture [20,65, 66]. Nearly all the large-scale fire tests conducted prior to the EUREKA tests focused on road tunnel issues. The EUREKA tests have filled the gap between road- and railway tunnels although there is still a great need for more testing of vehicles travelling through rail- and metro tunnels. In the EUREKA tests very little consideration was given to the risk of fire spread between vehicles, mainly because prior to and at the time of the performance of the tests there had not been that many serious large fire accidents involving multiple vehicles. This situation changed in the late 90's and in the beginning of $21^{\text {th }}$ century.

The Memorial tunnel test series [53] carried out between 1993 - 1995, represent another milestone in large scale tunnel testing although the fire source consisted of low sulfur No2 fuel oil pans (diesel) and not real vehicles. In the Memorial tunnel tests series there was a need for a well-defined fire source in order to compare the performance of the different ventilation systems.

During the early $21^{\text {st }}$ century there have been to date three fire test series performed in large-scale tunnels. Large-scale tests were performed in the No. 3 Shimizu Tunnel on the New Tomei Expressway using gasoline pan fires, cars and a bus [67]. These tests included natural and longitudinal ventilation as well as water sprinklers. In the Second Benelux tunnel in the Netherlands, large-scale tests with cars and Heavy Goods Vehicle (HGV) mock-ups using wood pallets, were performed in 2002 [68]. Tests with natural ventilation and longitudinal ventilation and water sprinkler systems were also performed here. Further, a large-scale test series was carried out in the Runehamar tunnel in 2003 [19, 40, 47, 48]. In Runehamar, four tests using a mock-up of HGV fire loads were carried out. These tests provide important information on fire development in different types of ordinary hazard goods and show that this type of goods can create fires which are similar in size to that of a gasoline tanker fire. During these tests an interesting phenomena concerning the pulsation of smoke was observed for the first time [48]. Based on the Runehamar tests, a new design values were recently adopted for the NFPA 502 standard (2008 edition) on HGV. Earlier design fires of $20-30$ MW had been adopted whereas in the 2008 version the design values have been changed to 70 - 200 MW with reference to the Runehamar tests. 
As the heat release rate is a key parameter for tunnel scientists and engineers, an overview of the most important heat release rate measurements in tunnels is given below.

\section{OVERVIEW OF MEASURED HEAT RELEASE RATES}

\section{Road vehicles}

The literature describes a number of measurements of heat release rates of road vehicles. The heat release rates for single passenger cars (small and large) vary from 1.5 to $8 \mathrm{MW}$, but the majority of the tests show heat release rate values less than $5 \mathrm{MW}$. When two cars are involved, the peak heat release rate varies between 3.5 and $10 \mathrm{MW}$. Further, there is a great variety in the time to reach the peak heat release rate, i.e., between 10 and 55 minutes.

Very few bus tests have been performed. The peak heat release rate from a standard bus is in the order of $30 \mathrm{MW}$ and the time to reach peak heat release rate is less than ten minutes.

The highest peak heat release rates are obtained for the HGV trailers. These have been found to be in the range of 13 to $202 \mathrm{MW}$, depending on the fire load. The time to reach peak heat release rate is in the range of 10 to 20 minutes. The fire duration is less than one hour for all the HGV trailer tests performed. In Figure 3 time-resolved heat release is shown for numerous HGV fire loads.

\section{Rail and metro vehicles}

The literature describes very few measurements of heat release rates for rail and metro vehicles. The majority of the tests available are from the EUREKA 499 test series. The peak heat release rate is found to be in the range of 7 to $43 \mathrm{MW}$ and the time to reach the peak heat release rate varies from 5 to 80 minutes, see Figure 3. If the fire were to spread between the train coaches, the total heat release rate and the time to reach the peak heat release rate would be much higher than the values given here.
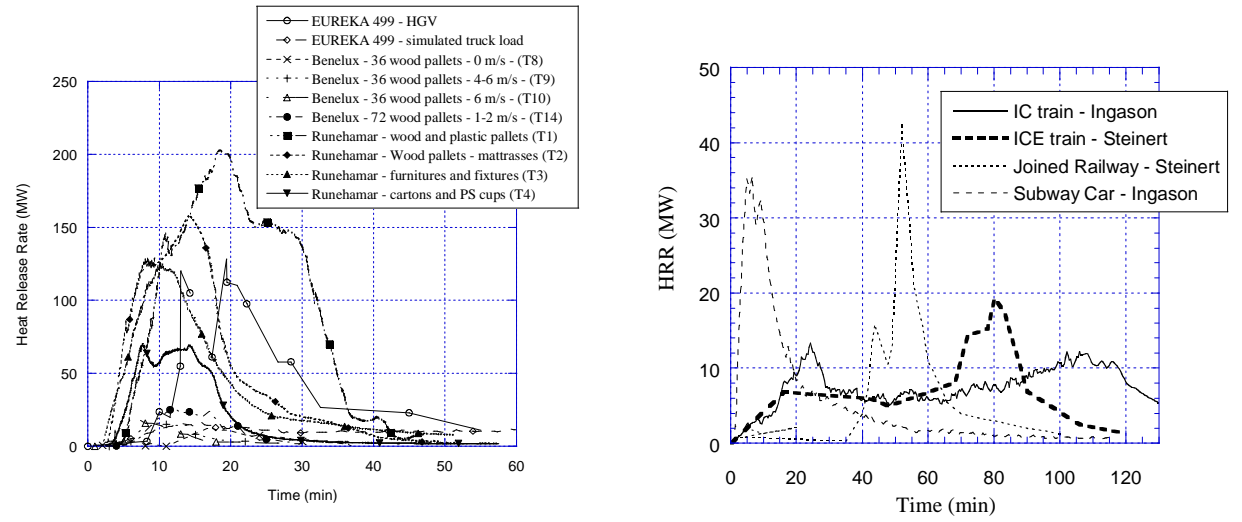

Figure 3 The heat release rate for the HGV trailer tests (left) and trains (right).

The EUREKA 499 tests show that there are many parameters that will affect the fire development in a train coach. These include the body type (steel, aluminum etc), the quality of the glazed windows, the geometry of the openings, the amount and type of combustible interior and its initial moisture content, the construction of wagon joints, the air velocity within the tunnel and the geometry of the tunnel cross-section. These are all parameters, which needs to be considered in the design process of a rail or metro tunnel.

Ingason [59] collected the heat release rate data from all the large scale tests available in the literature and normalized the maximum heat release to the exposed fuel surface area. The fuel surface area was defined as the freely exposed area where release of gasified fuel can occur simultaneously. The reason to normalize to the exposed fuel surface area was that this makes it convenient to compare the maximum heat release rate between different type of fuels and for different conditions. The results can easily be used to estimate the peak heat release rate in different type of vehicles and other solid and liquefied fuels. Based on this work, the heat release rate data was divided into three different groups based on the fuel type, i.e.; liquid pool 
fires, ordinary solid materials such as wood pallets and wood cribs and road and rail/metro vehicles. The data is summarized in Table 1.

Table 1 Summary of heat release rate per fuel surface area for liquid fires in tunnels. The tests have been performed in fuel pans with relatively deep fuel depth [59].

\begin{tabular}{|c|c|c|c|}
\hline Type of fuel & Test series & $\begin{array}{l}\text { Exposed fuel area } \\
\qquad\left(\mathrm{m}^{2}\right)\end{array}$ & $\begin{array}{l}\text { Maximum heat release } \\
\text { rate per square meter } \\
\text { exposed fuel area } \\
\mathrm{MW} / \mathrm{m}^{2}\end{array}$ \\
\hline \multicolumn{4}{|c|}{ Liquid } \\
\hline Gasoline & $\begin{array}{l}\text { Ofenegg, } \\
\text { Zwenberg, No.3 } \\
\text { Shimizu }\end{array}$ & $6.6,47.5,95$ & $0.35-2.6$ \\
\hline Kerosine & Glasgow & 1.44 & 1.4 \\
\hline n-Heptane & Eureka & 1,3 & 3.5 \\
\hline n-60 \% heptane/40\% toulene & 2nd Benelux & $3.6,7.2$ & $1.1-1.6$ \\
\hline Low-sulfur No 2 fuel oil & Memorial & $4.5,9,22.2,44.4$ & $1.7-2.5$ \\
\hline \multicolumn{4}{|c|}{ Solid fuel } \\
\hline Wood cribs & $\begin{array}{l}\text { Eureka (test 8, } 9 \\
\text { and 10) }\end{array}$ & 140 & $0.07-0.09$ \\
\hline Wood pallets & $\begin{array}{l}\text { 2nd Benelux (tests } \\
8,9,10 \text { and } 14 \text { ) }\end{array}$ & $\begin{array}{l}120 \text { (36 pallets) } \\
240 \text { (72 pallets) }\end{array}$ & $0.11-0.16$ \\
\hline $\begin{array}{l}82 \% \text { wood pallets and } 18 \% \text { PE } \\
\text { pallets }\end{array}$ & Runehamar (test 1) & 1200 & 0.17 \\
\hline $\begin{array}{l}82 \% \text { wood pallets and } 18 \% \\
\text { PUR matrasses }\end{array}$ & Runehamar (test 2) & 630 & 0.25 \\
\hline $\begin{array}{l}81 \% \text { wood pallets and cartons } \\
\text { and } 19 \% \text { plastic cups }\end{array}$ & Runehamar (test 4) & 160 & 0.44 \\
\hline HGV- furniture & Runehamar (test 3) & 240 & 0.5 \\
\hline HGV- furniture & Eureka (test 21) & 300 & 0.4 \\
\hline \multicolumn{4}{|c|}{ Vehicles } \\
\hline Medium sized passenger cars & $\begin{array}{l}\text { Assuming a } 5 \mathrm{MW} \\
\text { fire in the car }\end{array}$ & $12-18$ & $0.3-0.4$ \\
\hline Passenger car plastic & Test 20 in Eureka & 17 (no ceiling) & 0.35 \\
\hline Buss & Test 7 in Eureka & 80 & 0.36 \\
\hline Train & Test 11in Eureka & 145 & 0.30 \\
\hline Subway coach & Test 14 in Eureka & 130 & 0.27 \\
\hline
\end{tabular}

* The heat of combustion of gasoline is assumed to be equal to $43.7 \mathrm{MJ} / \mathrm{kg}, 43.5 \mathrm{MJ} / \mathrm{kg}$ for kerosene, $44.6 \mathrm{MJ} / \mathrm{kg}$ for n-heptane.

It was concluded that that the heat release data per square meter fuel surface area in a fuel controlled fire using different vehicles is rather narrow, i.e., between 0.3 to $0.4 \mathrm{MW} / \mathrm{m}^{2}$ [59]. This is also in line with the heat release rate per square meter fuel surface area for the solid materials. The heat release rate per square meter fuel surface area of the individual material exhibits a greater variation, but it appears that the total effect of the mixed material is not so broad. This observation is very important to consider when establishing design fires for tunnels. It is also important to perform more large scale tunnel fire tests using real vehicles. Most of the vehicle fire data is available for vehicles that are out of date, and therefore a new large scale tunnel test series with modern road and rail/metro vehicles is a pressing scientific endeavour.

\section{CONCLUSIONS}

This overview shows that the critical velocity for longitudinal flow in tunnels is the single most well investigated fire phenomena found in the tunnel fire research literature. Our knowledge in this area has reached a high level but there are still some issues that need to be investigated further. Very little work has 
been done on backlayering of smoke upstream a fire and any cross-sectional effects on heat release rates, temperatures, fire spread and toxic conditions. Extensive work using model scale tunnels has contributed new information and clarified many phenomena but the lack of good large scale experimental data is and will be a key issue in near future. This concerns mainly the correlation between heat release rate and maximum ceiling temperatures, the influence of ventilation on maximum heat release rate and fire growth rate and fire spread in and between vehicles. The extensive theoretical work which has been conducted concerning the effects of ventilation on heat release rates needs to be further investigated in large scale tests. Model scale tests contradict partly the results obtained from the probabilistic methods described here.

An interesting observation is that the heat release data per square meter fuel surface area in a fuel controlled fires of different vehicles is rather narrow. This needs to be validated for a broader range of vehicles. Most of the vehicles that have been tested in large scale tests are out of date, and therefore a new large scale tunnel test series with modern road and rail/metro vehicles is a pressing need. Of more academic interest is the pulsation obtained in the Runehamar tests. This phenomenon has been investigated to a small degree but it would be interesting to expend more efforts in this area.

\section{REFERENCES}

[1] Beard, A. N., and Carvel, R. O., Eds., "The handbook of tunnel fire safety," Thomas Telford Publishing, London, 2005.

[2] Ingason, H., "Fire Dynamics in Tunnels". In The Handbook of Tunnel Fire Safety (R. O. Carvel and A. N. Beard, Eds.), Thomas Telford Publishing, 231-266, London, 2005.

[3] Bettis, R. J., Jagger, S. F., and Wu, Y., "Interim Validation of Tunnel Fire Consequence Models: Summary of Phase 2 Tests", Health and Safety Executive, IR/L/FR/93/11, Buxton, Derbyshire, UK, 1993.

[4] Bettis, R. J., Jagger, S. F., Lea, C. J., Jones, I. P., Lennon, S., and Guilbert, P. W., "The Use of Physical and Mathematical Modelling to Assess the Hazards of Tunnel Fires", 8th International Symposium on Aerodynamics and Ventilation of Vehicle Tunnels, 439-469, Liverpool, 1994.

[5] Bettis, R. J., Daish, N., Jagger, S. F., and Linden, P. F., "Control of Smoke Movement Close to a Tunnel Fire", Second International Conference on Safety in Road and Rail Tunnels, 311-319, Granada, Spain, 3-6 April, 1995.

[6] Beard, A. N., Drysdale, D. D., and Bishop, S. R., "A Non-linear Model of Major Fire Spread in a Tunnel", Fire Safety Journal, 24, 333-357, 1995 doi:10.1177/073490419701500402.

[7] Beard, A. N., "A Model for Predicting Fire Spread in Tunnels", Journal of Fire Sciences, 15, July/August, 277-307, 1997 doi:10.1177/073490419701500402.

[8] Carvel, R. O., Beard, A. N., Jowitt, P. W., and Drysdale, D. D., "Variation of Heat Release Rate with Forced Longitudinal Ventilation for Vehicle Fires in Tunnels", Fire Safety Journal, 36, 6, 569-596, 2001 doi:10.1016/S0379-7112(01)00010-8.

[9] Carvel, R. O., Beard, A. N., and Jowitt, P. W., "CERBERUS: A New Model to Estimate Size and Spread for Fires in Tunnels with Longitudinal Ventilation", Proc. Int. Conf. on Tunnel Safety \& Ventilation, New Develeopments in Tunnel Safety, 69-76, Graz, Austria, 8-10 April, 2002.

[10] de Ris, J., "Duct Fires", Combustion and Science Technology, 2, 239-258, 1970 doi:10.1080/00102207008952252.

[11] Newman, J. S., and Tewarson, A., "Flame Propagation in Ducts", Combustion and Flame, 51, 347-355, 1983 doi:10.1016/0010-2180(83)90112-8.

[12] Newman, J. S., "Experimental Evaluation of Fire-Induced Stratification", Combustion and Flame, 57, 33-39, 1984 doi:10.1016/0010-2180(84)90135-4.

[13] Thomas, P., "The movement of buoyant fluid against a stream and the venting of underground fires", Fire Research Station, F.R. Note No. 351/1958, Boreham Wood, 1958. 
[14] Thomas, P. H., "The Movement of Smoke in Horizontal Passages Against an Air Flow", Fire Research Station, Fire Research Note No 723, 1968.

[15] Hinkley, P. L., "The Flow of Hot Gases Along an Enclosed Shopping Mall - A Tentative Theory", Fire Research Station, Fire Research Note No 807, 1970.

[16] Heselden, A., "Studies of fire and smoke behavior relevant to tunnels", 2nd Int Symp on Aerodynamics and Ventilation of Vehicle Tunnels, J1-1 -- J1-18, Cambridge, UK, 23-25 March, 1976.

[17] Grant, G. B., Jagger, S. F., and Lea, C. J., "Fires in tunnels", Phil. Trans. R. Soc. Lond., 356, 28732906, 1998.

[18] Heselden, A. J. M., "Studies of fire and smoke behaviour relevant to tunnels", Building Research Establishment, CP 66/78, Borehamwood, UK, 1978.

[19] Ingason, H., and Lönnermark, A., "Heat Release Rates from Heavy Goods Vehicle Trailers in Tunnels", Fire Safety Journal, 40, 646-668, 2005 doi:10.1016/j.firesaf.2005.06.002.

[20] Grant, G. B., and Drysdale, D., "Estimating Heat Release Rates from Large-scale Tunnel Fires", Fire Safety Science - Proceedings of the Fifth International Symposium, 1213-1224, Melbourne, 1995.

[21] Danziger, N. H., and Kennedy, W. D., "Longitudinal Ventilation Analysis for the Glenwood Canyon Tunnels", Fourth International Symposium on the Aerodynamics \& Ventilation of Vehicle Tunnels, 169-186, York, UK, 23-25 March, 1982.

[22] Oka, Y., and Atkinson, G. T., "Control of Smoke Flow in Tunnel Fires", Fire Safety Journal, 25, 305-322, 1995 doi:10.1016/0379-7112(96)00007-0.

[23] Atkinson, G. T., and Wu, Y., "Smoke Control in Sloping Tunnels", Fire Safety Journal, 27, 335341, 1996 doi:10.1016/S0379-7112(96)00061-6.

[24] Wu, Y., and Bakar, M. Z. A., "Control of smoke flow in tunnel fires using longitudinal ventilation systems - a study of the critical velocity", Fire Safety Journal, 35, 363-390, 2000 doi:10.1016/S0379-7112(00)00031-X.

[25] Lee, S. R., and Ryou, S., "An Experimental Study of the Effect of the Aspect Ratio on the Critical Velocity in Longitudinal Ventilation Tunnel Fires", Journal of Fire Sciences, 23, 119-138, 2005 doi:10.1177/0734904105044630.

[26] Hwang, C. C., and Edwards, J. C., "The critical ventilation velocity in tunnel fires-a computer simulation", Fire Safety Journal, 40, 213-244, 2005 doi:10.1016/j.firesaf.2004.11.001.

[27] Kunsch, J. P., "Simple Model for Control of Fire Gases in a Ventilated Tunnel", Fire Safety Journal, 37, 67-81, 2002 doi:10.1016/S0379-7112(01)00020-0.

[28] Vauquelin, O., "Parametric study of the back flow occurrence in case of a buoyant release into a rectangular channel", Experimental Thermal and Fluid Science, 29, 725-731, 2005 doi:10.1016/j.expthermflusci.2005.01.002.

[29] Vauquelin, O., and Telle, D., "Definition and experimental evaluation of the smoke "confinement velocity" in tunnel fires", Fire Safety Journal, 40, 320-330, 2005. doi:10.1016/j.firesaf.2005.02.004.

[30] Vauquelin, O., and Wu, Y., "Influence of tunnel width on longitudinal smoke control", Fire Safety Journal, 41, 420-426, 2006 doi:10.1016/j.firesaf.2006.02.007.

[31] Vantelon, J. P., Guelzim, A., Quach, D., Son, D., K., Gabay, D., and Dallest, D., "Investigation of Fire-Induced Smoke Movement in Tunnels and Stations: An Application to the Paris Metro", IAFSS Fire Safety Science-Proceedings of the third international symposium, pp. 907-918, Edinburg, 1991. 
[32] Ingason, H., "Model Scale Tunnel Fire Tests - Longitudinal ventilation", SP Swedish National Testing and Research Institute, SP REPORT 2005:49, Borås, Sweden, 2005.

[33] Beard, A. N., Drysdale, D. D., and Bishop, S. R., "Predicting the Effects of Design Parameter Variations on Major Fire Spread in a Tunnel", Int. Comm. Heat Mass Transfer, 23, 4, 495-504, 1996 doi:10.1016/0735-1933(96)00034-6.

[34] Beard, A. N., "Modelling Major Fire Spread in a Tunnel", Third International Conference on Safety in Road and Rail Tunnels, 75-86, Nice, France, 9-11 March, 1998.

[35] Beard, A. N., "Major Fire Spread in a Tunnel: A Non-linear Model", Fourth International Conference on Safety in Road and Rail Tunnels, 467-476, Madrid, Spain, 2-6 April, 2001.

[36] Beard, A. N., "Major Fire Spread in a Tunnel: A Non-linear Model with Flame Impingement", Proceedings of the 5th International Conference on Safety in Road and Rail Tunnels, 511-521, Marseille, France, 6-10 October, 2003.

[37] Rew, C., and Deaves, D., "Fire spread and flame length in ventilated tunnels - a model used in Channel tunnel assessments", Proceedings of the International Conference on Tunnel Fires and Escape from Tunnels, 397-406, Lyon, France, 5-7 May, 1999.

[38] Liew, S. K., and Deaves, D. M., "Eurotunnel HGV fire on 18th November 1996 - Fire devlopment and effects", Proceedings of the third International Conference on Safety in Road and Rail Tunnels, 29-40, Nice, France, 1998.

[39] Lönnermark, A., and Ingason, H., "Fire Spread and Flame Length in Large-Scale Tunnel Fires", Fire Technology, 42, 4, 283-302, 2006.

[40] Lönnermark, A., "On the Characteristics of Fires in Tunnels", In Department of Fire Safety Engineering, Lund University, Lund, Sweden, 2005.

[41] Carvel, R. O., Beard, A. N., and Jowitt, P. W., "The Effect of Forced Longitudinal Ventilation on a Pool Fire in a Tunnel", Interflam '99, 8th International Fire Science \& Engineering Conference, 1267-1272, Edinburgh, Scotland, 1999.

[42] Carvel, R. O., Beard, A. N., and Jowitt, P. W., "The Influence of Longitudinal Ventilation on Fire Size in Tunnel: Update", Fifth International Conference on safety in Road and Rail Tunnels, 431440, Marseille, France, 6-10 October, 2003.

[43] Carvel, R. O., Beard, A. N., and Jowitt, P. W., "Fire Spread Between Vehicles in Tunnels: Effects of Tunnel Size, Longitudinal Ventilation and Vehicle Spacing", Fire Technology, 41, 271-304, 2005.

[44] Ingason, H., "Heat Release Rate Measurements in Tunnel Fires", Second International Conference on Safety in Road and Rail Tunnels, 261-268, Granada, Spain, 3-6 April, 1995.

[45] Ingason, H., Nireus, K., and Werling, P., "Fire Tests in a Blasted Rock Tunnel", FOA, Report FOA-R-97-00581-990-SE, Sweden, 1997.

[46] Lönnermark, A., and Ingason, H., "The Effect of Cross-sectional Area and Air Velocity on the Conditions in a Tunnel during a Fire", SP Technical Research Institute of Sweden, SP Report 2007:05, Borås, Sweden, 2007.

[47] Lönnermark, A., and Ingason, H., "Gas Temperatures in Heavy Goods Vehicle Fires in Tunnels", Fire Safety Journal, 40, 506-527, 2005.

[48] Lönnermark, A., and Ingason, H., "Acoustic Considerations Regarding Pulsations during LargeScale Fire Tests in a Tunnel", 8th International Symposium on Fire Safety Science, 1473-1484, Beijing, China, 18-23 September, 2005.

[49] Harmathy, T. Z., "Experimental Study on the Effect of Ventilation on the Burning of Piles of Solid Fuels", Combustion and Flame, Vol. 31, p. 259-264, 1978. 
[50] Carvel, R. O., Beard, A. N., and Jowitt, P. W., "How Much do Tunnels Enhance the Heat Release Rate of Fires?" Proc. 4th Int. Conf on Safety in Road and Rail Tunnels, 457-466, Madrid, Spain, 2-6 April, 2001.

[51] Lönnermark, A., and Ingason, H., "The Influence of Tunnel Dimensions on Fire Size", Proceedings of the 11th International Fire Science \& Engineering Conference (Interflam 2007), 1327-1338, London, UK, 3-5 September, 2007.

[52] "Fires in Transport Tunnels: Report on Full-Scale Tests", edited by Studiensgesellschaft Stahlanwendung e. V., EUREKA-Project EU499:FIRETUN, Düsseldorf, Germany, 1995.

[53] "Memorial Tunnel Fire Ventilation Test Program - Test Report", Massachusetts Highway Department and Federal Highway Administration, 1995.

[54] Oka, Y., "Flame Behaviour in a Tunnel", Third International Conference on Safety in Road and Rail Tunnels, 159-168, Nice, France, 9-11 March, 1998.

[55] Kuwana, H., "Scale Effect on Temperature Properties in Tunnel Fire", Third International Conference on Safety in Road and Rail Tunnels, 87-96, Nice, France, 9-11 March, 1998.

[56] Jagger, S., and Grant, G., "Use of tunnel ventilation for fire safety". In The Handbook of Tunnel Fire Safety (A. N. Beard and R. O. Carvel, Eds.), Thomas Telford Publishing, 144-183, London, UK, 2005.

[57] "Rapport betreffende de beproeving van het gedrag van twee isolatiematerialen ter bescherming van tunnels tegen brand", Instituut TNO voor Bouwmaterialen en Bouwconstructies, Rapport B80-33, Delft, The Netherlands, 1980.

[58] Kurioka, H., Oka, Y., Satoh, H., and Sugawa, O., "Fire properties in near field of square fire source with longitudinal ventilation in tunnels", Fire Safety Journal, 38, 319-340, 2003.

[59] Ingason, H., "Fire Testing in Road and Railway Tunnels". In Flammability testing of materials used in construction, transport and mining (V. Apted, Ed.), Woodhead Publishing, 231-274, 2006.

[60] Haerter, A., "Fire Tests in the Ofenegg-Tunnel in 1965", International Conference on Fires in Tunnels, SP REPORT 1994:54, 195-214, Borås, Sweden, 10-11 October, 1994.

[61] Feizlmayr, A., "Research in Austria on tunnel fire, Paper J2, BHRA", 2nd Int Symp on Aerodynamics and Ventilation of Vehicle Tunnels, 19 - 40, Cambrigde, UK, 1976.

[62] Pucher, K., "Fire Tests in the Zwenberg Tunnel (Austria)", International Conference on Fires in Tunnels, 187-194, Borås, Sweden, 1994.

[63] ILF, "Brandversuche in einem Tunnel", Ingenieurgemeinschaft Lässer-Feizlmayr; Bundesministerium f. Bauten u. Technik, Strassenforschung, P0244, 1976.

[64] "State of the Road Tunnel Equipment in Japan - Ventilation, Lighting, Safety Equipment", Public Works Research Institute, Technical note, Vol. 61, Japan, 1993.

[65] Ingason, H., "Heat Release Rate Measurements in Tunnel Fires", International Conference on Fires in Tunnels, 86-103, Borås, Sweden, October 10-11, 1994, 1994.

[66] Steinert, C., "Smoke and Heat Production in Tunnel Fires", The International Conference on Fires in Tunnels, 123-137, Borås, Sweden, 10-11 October, 1994.

[67] Takekuni, K., "Disaster Prevention of Road Tunnel and Characteristics of the Evacuation Environment during Fires in Large Scale Tunnels in Japan", 4th Joint Workshop COB/JTA 2Joint Meeting JTA/Cob Open Work Shop 2001 in Netherlands, 35 - 43, 2001.

[68] Lemaire, A., van de Leur, P. H. E., and Kenyon, Y. M., "Safety Proef: TNO Metingen Beneluxtunnel - Meetrapport", TNO, TNO-Rapport 2002-CVB-R05572, 2002. 